\title{
Obesity aging linked to over sex more to get alzheimer's
}

\section{Abstract}

An extra fat can extra harmonised obesity and over sex worsens the effects of ageing on brain function. Corresponding angle of some natural sex restore the appearance of face. Unsymmetrical obese can lead over sex more likely to get Alzheimer's.
Volume 9 Issue 6 - 2018

\author{
Rahul Hajare \\ Indian Council of Medical Research, India
}

Correspondence: Rahul Hajare, Formerly Post-Doctoral Fellow, Indian Council of Medical Research, Department of Health Research, Ministry of Health and Family Welfare, India, Tel 0I I-26588590,Email rahulhalare@rediffmail.com

Received: November 02, 2018 | Published: November 27, 2018

\section{Introduction}

In brain-involved conditions such as Parkinson's and Alzheimer's, there is sometimes significant damage to brain cells. Embryonic cells have been shown through research to replenish damaged brain cells. ${ }^{1,2}$ This shows promise for the remediation of brain conditions. Basically, obese body cells are a not set of unindividualized cells that can be changed into other types of cells. It is this ability to change into different types of cells in body that makes obese cells so unique and important. They cannot help to regenerate other cells that have become diseased or damaged, thus keeping body not functioning well. A recent study has found that the combination of obesity and over sex could result in the development of Alzheimer's disease. ${ }^{3,4}$

\section{Data presentation, interpretations and discussions}

Annually, millions of deaths and disorders occur due to obese. Todays, tens of millions of obese around the world find themselves living and working in the Alzheimer's and in this marginalized state they do not only constitute a 'hidden' population since they are not under any adult or scheme and cannot be found in any national data, but the most vulnerable group to the risk factors for obese to over sex Alzheimer's that represent challenges to their emotional, social and academic development. ${ }^{5,6}$ Since adolescence is a critical stage in life and is the most transformative period, it is fundamental that brain is protected from the devastative effects off. To adequately protect them sex, it is critical that among other things their level of knowledge of attractive sex, perception towards it, level of knowledge of the causes of it in the community and among the normal living, level of knowledge of negative impacts of it, level of knowledge of the preventive methods; and level of knowledge of the support services and treatments needed by sex abusers is scientifically documented. ${ }^{7,8}$

\section{Level of knowledge of sex abuse}

In reacting to whether they have ever heard of over sex, all responded in the positive. However, they reacted differently in commenting what sex abuse means: sex illegal 18(31.03\%), drinking illegal sex 11(18.96\%), misused of sex $8(13.79 \%)$, excessive sex use $7(12.06 \%)$, unnatural sex use $6(10.34 \%)$, and others specified 5 $(8.62 \%)$. In a following up question as to whether they know any type of over sex in the community, the respondents reacted as illustrated obese 17 (26.15\%), extra obese 13(20.00\%), over sex 9(13.84\%), sex plus drug abuse $7(10.76 \%)$, sex plus inflammation ageing I5 (7.69\%), sex antibiotics $3(4.61 \%)$, etc. While the vast majority $28(93.33 \%)$ of the respondents claimed to have seen over sex in the community, in a related question as to the types of over sex they have seen in the community, they reacted as follow, alcohol + sex $19(21.83 \%)$, opium $+\operatorname{sex} 15(17.24 \%)$, marijuana $+\operatorname{sex} 14(16.09 \%)$, inhalant $+\operatorname{sex} 11$ $(12.64 \%)$, cocaine $+\operatorname{sex} 9(10.34 \%)$; and others specified $+\operatorname{sex} 8$ $(9.19 \%)$. In a follow up question as to whether sex abuse is happening in the community, the majority $17(68 \%)$ responded in the affirmative. In the same vein, majority $21(70 \%)$ acknowledged that sex abuse is happening in their community and have personally witnessed people being engaged in it either they are happy or it just assumption or dead living. In a related question as to the age range/bracket of the people they have seen abusing it, the respondents felt as follows, (18 to 22 ) $15(30 \%),(13$ to 17$) 12(24 \%),(23$ to 27$) 8(16 \%)$, ( 8 to 12 ) 7 $(14 \%)$, and (33 to 37$) 5(10 \%)$. In a follow up question as to why those sex are mostly abused, the participants reacted as illustrated quick drunkenness/high 17 (23.61\%), make one's work over and long $14(19.44 \%)$, easily accessible $11(15.27 \%)$, easily affordable 9 (12.50\%), long term drunkenness/high 7 (9.72\%), drunkenness not easily notice and others specified $5(6.94 \%)$ respectively.

\section{Conclusion}

Study showed link between obesity, sex performance. New study discovery showed one way the rapid expansion of human obesity and cognitive abilities of sex may have decreased. The same genes that have led to rapid decrease in cognitive abilities in humans may have also increased our susceptibility to psychiatric disease. Evolution of the human brain may have brought some psychiatric diseases can help increase extra circulation, stimulation the over sex drive.

\section{Acknowledgments}

None.

\section{Conflicts of interest}

The author declares that there were no conflicts of interest to report. 


\section{References}

1. Rahul Hajare. Is Loose Lower Wear Good for Sperm?. Int Gyn \& Women's Health. 2018;2(5): IGWHC.MS.ID.000148.

2. Rahul H. Why Indian men feel sad after sex. Int $J$ cell Sci \& mol biol. 2018;5(2):555658

3. Rahul Hajare. "Safe Sex: The True Principal Health? Medical Research and Clinical Case Reports. 2018;1(2):79-81.

4. Rahul Hajare. An Attempt to Eradicate Alcohol Dependency from Adult Men in Service Privately Managed Pharmaceutical Institutions in India. Toxicology and Applied Pharmacology Insights. 2018;1(1):1-4.
5. Rahul H. Indian Women, Trauma and Hydroxyl Drugs Dependency: Connections and Disconnections in Heart Disease for Women. Int J Curr Innov Adv Res. 2018;1(2):155-156.

6. Rahul Hajare. The Aggression is an Early Cause of Cancer. A Narrative Review of Classical to Modern Scientific Literature. Chronicle Med Surg. 2017;1(2):67-68.

7. Hajare R. The Curve Penis May Hold Secret to Cause of Cancer. A Profile of Primary Level Attending Review Treatment. J Nanomed Nanosci: $J N A N-143.2018$.

8. Rahul H. Indian Women, Trauma and Bisexual (FSF and FSM) Connections in Higher Risk for Heart Disease. Int Gyn \& Women's Health. 2018;2(3):IGWHC.MS.ID.000137. 